\title{
MODULATION OF MICROVASCULAR SMOOTH MUSCLE ADHESION AND MECHANOTRANSDUCTION BY INTEGRIN- LINKED KINASE
}

\author{
Shaoxing Huang ${ }^{1,{ }^{*}}$, Zhe Sun ${ }^{1,{ }^{*}}$, Zhaohui $\mathrm{Li}^{1}$, Luis A. Martinez-Lemus ${ }^{1,2}$, and Gerald A. \\ Meininger $^{1,2}$ \\ ${ }^{1}$ Dalton Cardiovascular Research Center, University of Missouri-Columbia, Columbia, MO 65211 \\ 2 Department of Medical Pharmacology and Physiology, University of Missouri-Columbia, \\ Columbia, MO 65211
}

\section{Abstract}

Objective-In this study we investigated the involvement of integrin linked kinase (ILK) in the adhesion of arteriolar vascular smooth muscle cells (VSMC) to fibronectin (FN) and in the mechano-responsiveness of VSMC focal adhesions.

\begin{abstract}
Methods-ILK was visualized in VSMC by expressing EGFP-ILK and it was knocked down using ILK-shRNA constructs. Atomic force microscopy (AFM) was used to characterize VSMC interactions with FN, VSMC stiffness and to apply and measure forces at a VSMC single focal adhesion (FA) site.
\end{abstract}

Results-ILK was localized to FA and silencing ILK promoted cell spreading, enhanced cell adhesion, reduced cell proliferation and reduced downstream phosphorylation of GSK-3 $\beta$ and PKB/Akt. AFM studies demonstrated that silencing ILK enhanced $\alpha 5 \beta 1$ integrin adhesion to FN and enhanced VSMC contraction in response to a pulling force applied at the level of a single FN FA site.

Conclusions-ILK functions in arteriolar VSMC appear linked to multiple signaling pathways and processes that inhibit cell spreading, cell adhesion, FA formation, adhesion to FN and the mechano-responsiveness of FN - FA sites.

\section{Keywords}

arterioles; mechanotransduction; mechanical forces; focal adhesions; shRNA silencing; atomic force microscopy (AFM); cell proliferation; fibronectin; extracellular matrix; integrin; microcirculation

\section{INTRODUCTION}

The interactions between cells and surrounding extracellular matrix (ECM) play important roles in many cellular processes, including differentiation, proliferation, migration, cytoskeleton organization and survival (Schwartz 1997; Adams 2001; Geiger, Bershadsky et al. 2001; Zaidel-Bar, Cohen et al. 2004). The integrin family plays an important role as a receptor for ECM proteins and as assembly points for cytoplasmic signaling and cytoskeletal

Address for correspondence: Gerald A. Meininger, Ph.D., Director, Dalton Cardiovascular Research Center, Margaret Proctor Mulligan Professor in Medical Research, Department of Medical Pharmacology and Physiology, 134 Research Park, Drive, University of Missouri-Columbia, Columbia, MO 65211, USA, Tel: 573-882-9662, Fax: 573-884-8432, meiningerg@ missouri.edu.

Authors contributed equally to this work. 
proteins. These multi-molecular assemblages of proteins form cellular focal adhesions that are critical for numerous cellular functions such as cell attachment, spreading, migration, proliferation, mechanical stability and cellular mechano-responsiveness (Wang, Butler et al. 1993; Schwartz 1997; Geiger, Bershadsky et al. 2001; Hynes 2002; Brakebusch and Fassler 2003; Zaidel-Bar, Cohen et al. 2004).

To date, at least ninety different focal adhesion molecules have been reported to localize to focal adhesions (Zaidel-Bar, Itzkovitz et al. 2007) and the list of focal adhesion proteins continues to expand. Focal adhesion molecules are typically categorized according to whether their localization is extracellular, transmembrane or cytoplasmic (Lo 2006). On the cytoplasmic side of the cell membrane these proteins assemble through protein-protein interactions with adaptor proteins that perform scaffolding functions linking signaling and/or cytoskeletal proteins with the cytoplasmic tail of the integrin beta subunit (Liu, Calderwood et al. 2000). First reported in 1996 (Hannigan, Leung-Hagesteijn et al. 1996), ILK was identified in a yeast 2-hybrid screen, and found to directly interact with cytoplasmic domains of $\beta 1, \beta 2$ and $\beta 3$ integrins. It was proposed that ILK was an important protein kinase that regulated integrin-mediated cell signaling. However, ILK is also described to possess non-kinase related scaffolding functions (Wu 2001; Wu and Dedhar 2001).

Since its initial discovery ILK activity has been shown to be involved in a number of cell functions. For example, a role for ILK has been proposed in a wide range of tissues and cell types for cell adhesion, proliferation, migration, matrix remodeling and survival (Brakebusch and Fassler 2003; Wu 2004). The ability of ILK to play a role in these activities is believed linked to its interactions with integrins and subsequently interaction with multiple downstream signaling pathways (Legate, Montanez et al. 2006). In rat aorta VSMC, ILK has been shown to modulate calcium-independent myosin diphosphorylation and contraction (Wilson, Sutherland et al. 2005) and mediate migration and proliferation (Friedrich, Clever et al. 2006). Recently, ILK has been shown to be part of a stable complex with PINCH and $\alpha$-parvin and the complex relocates from the cytosol to the cell periphery in response to acetylcholine stimulation in tracheal smooth muscle cells (Zhang, Wu et al. 2007). However, an understanding about a possible role for ILK in mechanical sensing in VSMC is incomplete. In this study, we investigated the role of ILK in rat VSMC by visualizing ILK distribution with an EGFP-ILK fusion construct and by RNAi silencing with an ILK-shRNA construct. We demonstrate here using atomic force microscopy that ILK-shRNA silencing in rat VSMC affects cell-matrix adhesion dynamics and the cellular response to mechanical force.

\section{MATERIALS AND METHODS}

\section{Cell isolation and culture}

VSMC were isolated from first-order feed arterioles of rat cremaster skeletal muscle using previously described methods (Wu, Mogford et al. 1998). Cells were cultured in DMEM/ F-12 (Invitrogen, Carlsbad, CA) supplemented with 10\% fetal bovine serum (FBS) and used in the experiments at passages 3-10.

\section{Plasmids and chemicals}

EGFP-C3 was kindly provided by Dr. Min Lee (University of Missouri-Columbia). EGFPILK was a gift from Dr. Cary Wu (University of Pittsburg). Two ILK-shRNA constructs (Clone ID: V2HS_202919 and V2HS_48753, denoted as ILK-O and ILK-H in the following text) targeting different sites of rat ILK (GenBank accession number: NM_133409; targeting sites: 737-755 and 1019-1037) were purchased from Open Biosystems (Huntsville, AL). Negative control shRNA pRS plasmid was purchased from Origene Technologies 
(Rockville, MD). Antibody for anti-ILK and anti-phospho-Akt1 were purchased from Upstate (Lake Placid, New York). Anti-vinculin antibody was from Biogenesis (England, UK). $\beta$-actin antibody was from Sigma (St. Louis, MO). Antibody for Hic-5 was obtained from BD Biosciences (San Jose, CA). Antibodies for Akt1, GSK-3 $\beta$ and phospho-specificGSK-3 $\beta$ were from Santa Cruz Biotechnology (Santa Cruz, CA). Fibronectin (FN) was purchased from Invitrogen (Carlsbad, CA) and collagen type I (CN I) was from BD Biosciences (San Jose, CA).

\section{Cell transfection and selection of stably transfected cells}

Cells were transfected with Fugene 6 reagent as described by the manufacturer (Roche, Indianapolis, IN). The ratio of Fugene 6 to DNA was maintained at $3 \mu \mathrm{l}$ of Fugene $6: 2 \mu \mathrm{g}$ of plasmid DNA. Briefly, $6 \mu$ of Fugene 6 reagent was mixed with $94 \mu \mathrm{l}$ of serum-free medium and incubated at room temperature for $5 \mathrm{~min}$, and then $4 \mu \mathrm{g}$ of DNA was added to the mixture and incubated for $45 \mathrm{~min}$. This mixture was drop wise added to cells resuspended in $2 \mathrm{ml}$ fresh regular culture medium at the density of $10^{5} / \mathrm{ml}$, mixed well and returned to the incubator. Cells were used 4-6 days after the start of transfection. Images of cells were acquired using an Olympus Fluoview 1000 confocal microscope. For selection of ILK-shRNA stably transfected cells, six days after transfection, cells were treated continuously with $2.5 \mu \mathrm{g} / \mathrm{ml}$ puromycin (Invitrogen, Carlsbad, CA) for 4 weeks. Stably transfected cells were harvested and frozen in liquid nitrogen. To minimize clonal variability, frozen cells were thawed and cultured for further experiments once every 4 weeks.

\section{Cell-adhesion assay}

The adhesion assay was performed in 96-well plates coated with $50 \mu \mathrm{g} / \mathrm{ml}$ collagen or $50 \mu \mathrm{g} /$ $\mathrm{ml} \mathrm{FN}$ overnight at $4^{\circ} \mathrm{C}$. After coating, the wells were washed with PBS and blocked with $0.1 \%$ BSA in DMEM/F-12 for 1 hour at $37^{\circ} \mathrm{C}$. Cells were detached with trypsin, resuspended in serum free DMEM/F-12 containing $0.1 \%$ BSA and $100 \mu$ lof cells $\left(2 \times 10^{5}\right.$ \% $\mathrm{ml}$ ) was added to each well and incubated at $37^{\circ} \mathrm{C}$ for $1 \mathrm{~h}$. Non-adherent cells were removed by washing with PBS two times and remaining cells were fixed with $2 \%$ paraformaldehyde for 15 minutes at room temperature. Adherent cells were washed and stained with Crystal Violet $(1 \mathrm{mg} / \mathrm{ml}$ in distilled water) for 10 minutes. After washing with water, the plates were dried and $50 \mu \mathrm{l}$ of $2 \%$ SDS was added to each well. The plates were incubated at room temperature for $30 \mathrm{~min}$ and then read at $560 \mathrm{~nm}$ using a Bio-Tek Synergy HT plate reader.

\section{Cell migration assay}

Cell migration assay was performed as previously described (Chao, Martinez-Lemus et al. 2006). Briefly, A 48-well Boyden chamber and filters with pores of $8 \mu \mathrm{m}$ (Neuro Probe, Gaithersburg, MD) were used. Each filter was coated with poly-L-lysine at $4{ }^{\circ} \mathrm{C}$ overnight. Thirty microliters of DMEM/F-12 with $0.1 \%$ BSA were placed in each well of the lower chamber. Chemottractant were added in lower chambers (PDGF: platelet derived growth factor, $2.5 \mu \mathrm{g} / \mathrm{ml}$; or FN: fibronectin, $50 \mu \mathrm{g} / \mathrm{ml}$; null: un-stimulated control). Fifty microliters of cells $\left(4 \times 10^{5} / \mathrm{ml}\right)$ was placed in the upper chamber and incubated for $3 \mathrm{~h}$ at $37^{\circ} \mathrm{C}$ with $5 \%$ $\mathrm{CO}_{2}$. Cells in the upper chamber of the filter and non-migrating cells on the topside of the filters were removed. Migrated cells on the lower side of the filter were fixed and stained with Diff-Quik stain kit (Fisher Scientific, Pittsburg, PA) and washed with water. The filters were scanned and staining intensity of migrated cells was calculated using a densitometric method (NIH Image J). 


\section{Cell proliferation assay}

Cells were plated on $35 \mathrm{~mm}$ cell culture dishes, and are cultured in incubator at $37^{\circ} \mathrm{C}$ with $5 \% \mathrm{CO}_{2}$ in regular VSMC culture media. A square $(5 \times 5 \mathrm{~mm})$ was then printed on the dishes, cells growing within the square were counted using a phase contrast microscope (Nikon TMS) equipped with a 10X objective, starting from the end of day 1 till the end of day 5. The data was then normalized to cell numbers of day 1 to estimate a cell proliferation curve.

\section{Western blot analysis}

Cells were washed with ice-cold PBS and lysed for $30 \mathrm{~min}$ in CSK buffer $(50 \mathrm{mM} \mathrm{NaCl}$, $300 \mathrm{mM}$ sucrose, $3 \mathrm{mM} \mathrm{MgCl} 2,10 \mathrm{mM}$ PIPES at pH6.8), with a complete protease inhibitor cocktail (Roche, Indianapolis, IN) and $1 \mu \mathrm{g} / \mathrm{ml}$ pepstatin. Protein concentrations were determined using the BCA Protein Assay Kit from PIERCE (Rockford, IL). Equal amounts of proteins were loaded on SDS-PAGE and transferred to PVDF membranes using the NuPAGE electrophoresis system (Invitrogen, Carlsbad, CA). To identify specific protein band, $10 \mu \mathrm{l}$ of the Precision Plus Protein Standards (Kaleidoscope) from Bio-Rad (Hercules, CA) was also loaded on each gel. The membrane was then incubated in blocking buffer (TBS containing $2 \%$ milk and $0.1 \%$ Tween 20 ) with primary antibody at $4{ }^{\circ} \mathrm{C}$ overnight. After washing, the membrane was visualized using the Visualizer Western Blot Detection Kit (Millipore, Billerica, MA). Immunoblots were then stripped using Stripping Buffer II (Upstate, Lake Placid, New York) and re-probed with $\beta$-actin antibody as a loading control. The protein bands on the films were quantified using DNR's GelQuant software (DNR BioImaging Systems Ltd, Jerusalem, Israel) and normalized to the corresponding $\beta$-actin band.

\section{Immunofluorescence and confocal laser scanning microscopy}

Cells grown to 50-70\% confluency were plated on glass-bottom tissue culture dishes (35 $\mathrm{mm}$ ) overnight. After being fixed with $2 \%$ paraformaldehyde at room temperature for 20 min and washed twice with $0.1 \mathrm{mM}$ glycine buffer, cells were incubated with primary antibodies (1:200 dilution) in antibody buffer $\left(15 \mathrm{mM} \mathrm{Na}_{3} \mathrm{C}_{6} \mathrm{H}_{5} \mathrm{O}_{7}, 150 \mathrm{mM} \mathrm{NaCl}, 2 \%\right.$ BSA, $0.05 \%$ Triton $\mathrm{X}-100)$ at $4{ }^{\circ} \mathrm{C}$ overnight. After cells were washed with cold washing buffer $\left(15 \mathrm{mM} \mathrm{Na}_{3} \mathrm{C}_{6} \mathrm{H}_{5} \mathrm{O}_{7}, 150 \mathrm{mM} \mathrm{NaCl}, 0.05 \%\right.$ Triton X-100) at room temperature 6 times, cells were incubated with Alexa 488-conjugated secondary antibody (goat anti-

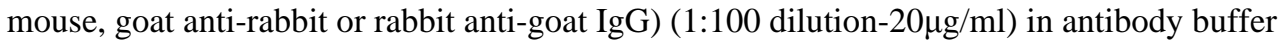
and/or Alexa 568-conjugated phalloidin (1:100 dilution) in a dark environment at room temperature for $1 \mathrm{~h}$. After being washed with cold washing buffer, images of the cells were taken on an Olympus Fluoview 1000 confocal microscope using excitation wavelengths of $488 \mathrm{~nm}$ and $561 \mathrm{~nm}$, respectively. Analysis of the images was undertaken with the Olympus Fluoview 1000 software.

All procedures in the present study followed institutional guidelines and were approved by the University of Missuri Animal Care and Use Committee. Rat cremaster muscle feed arteriole was isolated and cannulated using glass micropipettes as described previously (Falcone, Davis et al. 1991). The vessel was pressurized to $60 \mathrm{mmHg}$ at $34^{\circ} \mathrm{C}$. After the vessel established myogenic tone, it was fixed by incubating in $2 \%$ paraformaldehyde at room temperature for $1 \mathrm{hr}$ followed by $2 \mathrm{X}$ washing ( $5 \mathrm{mins}$ each) with $0.1 \mathrm{mM}$ glycine buffer. The vessel was then washed 3 times with DPBS, and incubated with primary antibody (1:200 dilution) in antibody buffer at $4{ }^{\circ} \mathrm{C}$ overnight. After $3 \mathrm{X}$ washing, the vessel was incubated with Alexa 488-conjugated secondary antibody (goat anti-mouse $\operatorname{IgG})$ (1:100 dilution- $20 \mu \mathrm{g} / \mathrm{ml}$ ) in a dark environment at room temperature for $1 \mathrm{~h}$. The vessel was then washed again in washing buffer, and incubated with propidium iodide (PI, $20 \mu \mathrm{M}$ ) for 15 mins, followed by $3 X$ washing with DPBS. The stained vessel was visualized on a Leica- 
SP5 confocal microscope, with excitation wavelength of $488 \mathrm{~nm}$, and fluorescence emission was collected at $495-550 \mathrm{~nm}$ for Alexa488 and $650-700 \mathrm{~nm}$ for PI.

\section{Quantification of focal adhesions}

For quantification of the number of focal adhesions per cell, vinculin-labeled fluorescent images of ILK-shRNA and non-silenced control cells were analyzed with NIH Image J software. Confocal image planes of the cell bottom (cell substrate interface) that clearly showed focal adhesions were selected for analysis. RGB color images were converted to eight-bit black and white images using the image color RGB split function so that focal adhesions appeared as the black pixels. Focal adhesions were defined using Image $\mathbf{J}$ software by setting an intensity threshold. Image processing was identical for all cells in the different experimental groups. The number of focal adhesions per cell was counted using the analyze particles function.

\section{Atomic force microscopy}

Measurement of the cell's mechanical response to pulling force applied through FN was carried out as previously described (Sun, Martinez-Lemus et al. 2005). Briefly, an atomic force microscope (AFM) (model IVa, Veeco Mertrology Inc., Santa Barbara, CA) was mounted on an inverted microscope (Olympus IX81 Olympus Inc., Long Island, NY). The AFM was used in contact mode operation. A 5- $\mu \mathrm{m}$ bead with PEG-biotin coating was coupled to the tip of a silicon nitride cantilevers with spring constant of $0.01 \mathrm{~N} / \mathrm{m}$ (Novascan, Ames, IA). The cantilever-coupled bead was first washed with Dulbecco's phosphate-buffered saline (DPBS), followed by incubating with $3 \mathrm{mg} / \mathrm{ml}$ avidin (Sigma, St. Louis, MO) for $10 \mathrm{~min}$ at room temperature. After washing with DPBS, the beads were incubated with $1 \mathrm{mg} / \mathrm{ml}$ biotin-conjugated FN for $10 \mathrm{~min}$, followed by washing with DPBS. The probes with FN-coupled beads were brought into contact with the cell surface using AFM. The FN-coated bead was allowed to interact with the cell surface for 20 min prior to a pulling experiment. We have previously determined that $20 \mathrm{~min}$ of contact is sufficient to allow formation of a focal adhesion connection between the cell and the FN coated microbead (Sun, Martinez-Lemus et al. 2008). An upward pulling force ( $~ 800 \mathrm{pN}$, step increase) was then applied to the bead using the AFM, the bead displacement was then recorded as a cantilever deflection in the AFM height image. As the bead was connected to the cell, the recordings of bead displacement subsequent to the pull represented the mechanical response of VSMC at the connection site. Experiments were performed at room temperature in DMED/F-12 medium without phenol red. AFM data was analyzed using Nanoscope and Matlab software (Math-Works, Natick, MA). To further quantify and compare the cellular mechanical response, data were analyzed and the response expressed as fractional compensation $\left(f_{c}\right)$ according to the formula:

$$
f_{c}=\left(D_{A F M}-D_{\text {cell }}\right) / D_{A F M}
$$

$D_{A F M}$ : the initial distance that bead was lifted following the pull with the AFM cantilever (Fig. 9A).

$D_{c e l l}$ : the ending distance that the bead was from its pre-pulling position after the cell's local contractile response (Fig. 9A).

To measure the rupture force and adhesion probability between FN and cell, AFM probes were washed with water, followed by incubating with PEG (Molecular weight: $8000,1 \mathrm{mg}$ / $\mathrm{ml}$ ) at room temperature for $10 \mathrm{~min}$. After being washed with water, the probes were coated with FN (1 mg/ml) for $10 \mathrm{~min}$. The probes were then washed with DPBS and mounted onto the AFM. The AFM was operated in force mode so that probes were approached, made 
contact and retract from the surface of the cell cyclically. The adhesion sampling parameters involved a contact duration of $\sim 0.5 \mathrm{~s}(1 \mathrm{~Hz})$ and contact force of $\sim 300 \mathrm{pN}$. During AFM probe retraction, adhesions were detected as abrupt shifts (Fig 8A) in the retraction curve in contrast to the smooth curve recorded during the tip approach (Illustrations of cantilever configuration at different stages of a force curve were shown in Fig. 8A). The abrupt shift in the retraction curve representing the force required to cause adhesion bond failure between the AFM probe and the cell. The cell compression stiffness was analyzed by fitting the approach portion of the force curve (the blue curve as shown in Fig 8A) with Hertz model. (Radmacher 1997; Trache, Trzeciakowski et al. 2005) For experimental groups, 500-600 force curves were sampled from each of ten randomly selected cells (50-60 curves/cell) with each probe. The adhesion probabilities were calculated as: (the number of force curves with detectable adhesion events)/(the number of total force curves). The rupture force of integrinECM bindings and the cell compression stiffness were analyzed using NforceR (Proprietary software, copyright registration number TXu1-328-659).

\section{Statistical analysis}

Data are presented as means \pm SEM. Each experiment was repeated a minimum of three times and representative results are shown. Statistical analyses were performed using the Student $t$-test using Microsoft Excel and ANOVA analysis using SAS9.1. $P<0.05$ was considered statistically significant.

\section{RESULTS}

\section{Integrin-linked kinase localized to focal adhesions in VSMC}

To investigate the localization of ILK two methods were used. In live VSMC, cells were transfected with an EGFP-ILK construct. As shown in Figure 1A, EGFP-ILK is localized to focal adhesions whereas EGFP (Figure 1B) alone was diffusely dispersed throughout the cell. Immuo-histochemistry using ILK-specific antibody also shown the abundant presence of ILK (green) in the vascular smooth muscle in isolated rat cremaster feed arteriole (Figure 1C). Immunofluorescent experiments on fixed cells labeled with both anti-ILK and antivinculin antibodies showed that ILK localized to focal adhesions with vinculin (Figure 2). ILK-silencing reduced the ILK specific fluorescent labeling in the cells (Figure 2).

However, ILK co-localization with vinculin focal adhesions was not affected in the ILKsilenced VSMC comparing to the non-silenced control cells (Figure 2). Similar to silenced cells, ILK localization to sites of vinculin accumulation at focal adhesions was also observed in cultured freshly isolated VSMC (data not shown). These results indicated that silencing was not altering distribution but only the level of ILK expression.

\section{Integrin-linked kinase silencing}

To knock down the cellular levels of ILK, VSMC cells were stably transduced with two different ILK-shRNA constructs, ILK-O and ILK-H respectively. A non-silenced negative construct was used as a control. As shown by western blotting (Figure 3A), after RNAi silencing, the ILK expression level decreased to $18 \pm 3 \%$ of that of non-silenced control cells with the ILK-O shRNA ( $\mathrm{n}=3$ ), and decreased to $30 \pm 10.8 \%$ of control cells with the ILK-H shRNA ( $\mathrm{n}=3)$. Immunofluorescent labeling of VSMC with anti-ILK antibody also showed that ILK expression was significantly reduced in VSMC stably transfected with either of the ILK-shRNA constructs (Figure 3B). The images shown were through focus whole cell images of VSMC. It can be seen that ILK also diffusively distributed across the cytosol, whereas the signals from focal adhesions ILKs were mixed with cytosolic signals, and cannot be clearly seen. 
It has been shown that ILK induces phosphorylation of GSK-3 $\beta\left(\operatorname{Ser}^{9}\right)$ and PKB/Akt $\left(\mathrm{Ser}^{473}\right)$ in diverse cell lines (Delcommenne, Tan et al. 1998; Lynch, Ellis et al. 1999; Nho, Xia et al. 2005; Qian, Zhong et al. 2005). As a further test of ILK silencing we examined whether ILK silencing would result in reduced phosphorylation of these downstream signaling targets of ILK. Western blots were performed using proteins from cells stably transfected with ILK-O shRNA and non-silenced control. In ILK silenced cells a decrease was observed in phosporylation of both GSK-3 $\beta$ ( $67 \pm 5 \%$ of control) and PKB/Akt (72 \pm $6 \%$ of control). This data further confirmed that ILK expression and associated signaling was significantly inhibited in these cells.

\section{Integrin-linked kinase silencing enhanced cell spreading in VSMC}

To examine the effects of ILK silencing on cell spreading in VSMC, ILK-O and nonsilenced control cells were plated on $50 \mu \mathrm{g} / \mathrm{ml} \mathrm{FN}$ for 1,3 and $5 \mathrm{~h}$, fixed and then actin was labeled with Alexa 568-conjugated-phalloidin (Figure 4A). Images were taken with a confocal microscope and cell areas were quantified with NIH Image J software. ILK-shRNA cells exhibited more spreading at all time points (Figure 4B), although the spreading increase in ILK-O compared to control decreased from $3.7 \pm 0.5$ to $1.4 \pm 0.04$-fold after 3 hours (Figure 4B).

\section{Integrin-linked kinase silencing inhibited cell migration and proliferation of VSMC}

To further evaluate and confirm the effect of ILK silencing, studies were performed to assess the effects of silencing on VSMC migration and proliferation. Migration assays were performed using a Boyden migration chamber on control cells and on cells transfected with either ILK-O or ILK-H shRNAs. Migration was evaluated under the conditions in which the lower chambers included no stimulant (null, un-stimulated control), $50 \mu \mathrm{g} / \mathrm{ml}$ soluble FN or platelet derived growth factor (PDGF, $2.5 \mu \mathrm{g} / \mathrm{ml}$ ). As shown in Figure 5A, soluble FN was a very strong chemotactic for VSMC whereas PDGF showed no effect on VSMC migration. ILK silencing significantly inhibited VSMC migration by FN. A cell counting proliferation assay was also carried out on cells transfected with non-silenced control and ILK-shRNA to examine if ILK silencing had any effect on VSMC proliferation. The results indicated that, comparing to CK4, ILK silencing significantly reduced VSMC cell proliferation in both ILK-O and ILK-H cell lines (Figure 5B).

\section{Integrin-linked kinase silencing altered focal adhesions and enhanced cell adhesion in VSMC}

Several methods were used to evaluate the effects of ILK silencing on cell adhesion. A cell plate adhesion assay indicated that ILK silencing enhanced cell adhesion in VSMC by $1.3 \pm$ 0.17 -fold on collagen I substrate $(n=6, p<0.05$ vs. control) and $1.5 \pm 0.28$-fold on fibronectin substrate ( $\mathrm{n}=6, \mathrm{p}<0.05$ vs. control) (Figure 6A). In a separate series of experiments, VSMC were immunofluorescently labeled with an anti-vinculin antibody to visualize and quantify the number of focal adhesions (e.g. Figure 6B). For both ILK-O and ILK-H silenced cells on fibronectin substrate, the number of focal adhesions per cell was increased compared to nonsilenced control cells (Figure $6 \mathrm{C})(\mathrm{n}=22, \mathrm{p}<0.01$ vs. control).

Further studies were conducted to examine the effects of ILK silencing on three focal adhesion proteins, vinculin, paxillin and Hic-5. Vinculin expression was examined in ILK-O cells using Western blotting and was increased compared to non-silenced control cells (162 $\pm 6 \%$ of control; $n=3$ ) (Figure $6 \mathrm{D}$ ). In contrast to vinculin, paxillin expression was significantly decreased $(30 \pm 6 \% ; n=3$ and $44 \pm 6 \%$ of control; $n=3)$ in both ILK-O and ILK$\mathrm{H}$ transfected VSMCs. In contrast to paxillin, the paxillin homologue protein Hic-5 was

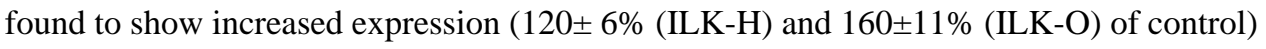
following ILK silencing (Figure 7A). The different effects of ILK silencing on paxillin and 
Hic-5 were also observed by immunocytochemistry experiments. (Figure 7B) Collectively, these data indicate that ILK silencing is correlated with enhanced cell adhesion in VSMC, and it differentially affects vinculin, Hic-5 and paxillin expression.

\section{AFM measurements show Integrin-linked kinase silencing enhanced VSMC integrin-FN adhesion, lowered cell mechanical stiffness and enhanced mechanoresponsiveness of focal adhesions}

Further investigation of adhesion to FN was performed using AFM to directly evaluate the effects of ILK silencing on single molecule adhesion of FN to VSMC integrins and to quantify cell stiffness. Figure 8A illustrates a typical adhesion force curve, the abrupt jump in the retraction curve (red) represents the rupture of an adhesion between FN and the cell. The number of adhesion events and the force required to rupture the adhesions was quantified from the retraction curves. The approach curve was used to fit the classic Hertz model to estimate the compression stiffness of the cell. ILK silenced cells exhibited a significantly increased number of adhesions to $\mathrm{FN}$, indicative of an increase in integrin binding activity ( $\mathrm{n}=20, \mathrm{p}<0.05$ vs. control) (Figure $8 \mathrm{~B}, \mathrm{C}$ ). In addition, the stiffness of VSMC was decreased by $20 \%$ in ILK-O cells (Figure 8D) suggesting that ILK silencing results in reduced tension in the cortical actin filament layer.

The mechanoresponsiveness of single focal adhesion sites formed with a $5 \mu \mathrm{m}$ dia FN coated bead was assessed by applying a $\sim 800 \mathrm{pN}$ pull to the focal adhesion site. In ILK-O silenced cells the resistance to pull was significantly increased such that deformation of the silenced cell showed an apparent pulling elasticity of $9.3 \mathrm{pN} / \mathrm{nm}$ compared to $5.5 \mathrm{pN} / \mathrm{nm}$ in control cells (Figure 9C) indicating a tight adhesion and stiff underlying cytoskeletal support of the adhesion. Following the initial upward deformation of the cell after pull, both the ILK silenced and control cells mechanically responded by pulling the FN coated bead back toward the cell surface. However, the compensatory mechanical response generated by the ILK silenced cells was significantly greater than in the control cells $(55.5 \%$ vs $22.5 \%$ compensation or return toward initial position) (Figure 9B).

\section{DISCUSSION}

Interactions between VSMC and the ECM are critical for its normal numerous functions as well as being regarded as important in VSMC responses to injury (Legate, Montanez et al. 2006; Dwivedi, Sala-Newby et al. 2008; Ho, Hou et al. 2008; Ho and Bendeck 2009). Roles in cell proliferation, migration, cell spreading, cytoskeletal assembly and contraction have been demonstrated for ILK. Collectively, this suggests our understanding of this important kinase is complex and incomplete. In smooth muscle, ILK has been shown to play a role in tracheal smooth muscle in the regulation of actin polymerization, protein scaffolding at focal adhesions and tension development (Zhang, Wu et al. 2007), and has been identified to directly phosphorylate the myosin light chain (MLC) (Deng, Van Lierop et al. 2001) as well as the myosin phosphatase target subunit (MYPT) (Muranyi, MacDonald et al. 2002) in chicken gizzard smooth muscle. There is also considerable interest in the role of ILK in the response of VSMC to injury as it appears directly involved in altering proliferation, migration and intimal thickening. However, contradictory observations have been reported for the functional role of ILK in injury-induced aortic atherogenesis. Ho et. al reported that ILK expression decreased in the neointimal VSMC layers of the aorta, and by using ILK silencing with siRNA in cultured VSMCs found that this would facilitate VSMC migration and proliferation (Ho, Hou et al. 2008). In contrast, Friedrich et al. and Dwivedi et al. showed an increased ILK expression in neointima VSMC, and by using ILK silencing with siRNA or dominant negative ILK mutants in cultured VSMCs found that decrease of ILK expression or activity inhibited cell migration and proliferation. (Legate, Montanez et al. 2006; Dwivedi, Sala-Newby et al. 2008). Therefore, despite accumulating knowledge, 
current evidence leads to the conclusion that there is, as of yet, no totally uniform picture of the functional role of ILK in VSMC.

In the present study, we sought to explore the roles of ILK in regulation in cell adhesion as it relates to mechanotransduction and mechanosensing in VSMC (isolated from rat skeletal muscle arteriole). Cells were used that were stably expressing ILK-shRNA constructs (ILKO) or a non-silenced negative control cells. Reduction of ILK level (18 $\pm 3 \%$ of control) in cultured VSMC stably expressing ILK-shRNA resulted in an increase in cell spreading, cell adhesion and focal adhesion formation, and modulated the cellular response to stretch. ILK silencing with a second shRNA construct (ILK-H) also suppressed ILK expression in VSMC ( $30 \pm 10.8 \%$ of control level) produced similar effects as ILK-O, such that it increased vinculin at focal adhesions, decreased paxillin expression and hindered VSMC migration and proliferation. Confirmation of these observations with shRNAs indicates that these effects are ILK-related, and not due to non-specific actions of a particular shRNA.

The findings that ILK knock-down induced strong integrin-FN focal adhesions (FA) and enhanced integrin-FN bindings strongly suggested that ILK activity normally acts to negatively regulate 1) the adhesive activity (i.e. binding with ECM proteins) of integrins, and 2) the FA association with cytoskeletal elements or scaffolding. This implication of ILK function fits in the context with the other observations in our study. It is reasonable to interpret the enhanced integrin-FN binding seen with the AFM as being functionally related to the enhanced cell adhesion and enhanced cell spreading. Development of stronger focal adhesions in ILK silenced cells are also consistent with decrease observed in VSMC migration. Of particular relevance to our hypothesis was the observation that ILK silencing increased the strength and elasticity of single focal adhesions formed with the AFM attached and FN coated microbeads. In addition, these FN focal adhesion sites were more mechanoresponsive to mechanical force applied as a vertical pulling force with the AFM. These observations suggest a key role for ILK in mechanical coupling of VSMC to the ECM and in modulating the mechanosensitivity of those attachment sites.

It is important to note that the elasticity and cell stiffness measurements are conducted using two different approaches and they yield two different indices of the cellular properties. The stiffness as shown in Figure 8D was calculated from the approach curves in force mode operation of the AFM (Fig. 8A). It is a point sample measurement and reflects the net tensional forces in the sampled region. The reduced cell stiffness of ILK-silenced cells suggested that ILK could be involved in the tension development of VSMC, which is probably related with its role as a kinase for MLC and MYPT (Deng, Van Lierop et al. 2001; Muranyi, MacDonald et al. 2002). By comparison, the elasticity measured following pulling provides a mechanical assessment of the strength of the attachments to the FNcoated, AFM microbead tip, which reflects the mechanical strength of cytoskeleton connected with the focal adhesion at the bead contact site. The higher puling elasticity (Figure. 9C) indicates that the cellular adhesions formed around the FN-coated beads and corresponding underlying cytoskeletal attachments are stronger than in the control cells.

The functions of ILK have been investigated in diverse cell types by several different strategies including knockdown of ILK expression using synthesized small interfering double-stranded RNA (siRNA) (Attwell, Mills et al. 2003; Troussard, Mawji et al. 2003; Xu, Fukuda et al. 2005; Zhang, Ikegami et al. 2006), short hairpin RNA (shRNA) (Brummelkamp, Bernards et al. 2002; Paddison, Caudy et al. 2002) or dominant negative mutants (Ishii, Furuoka et al. 2003; Leung-Hagesteijn, Hu et al. 2005; Rosano, Spinella et al. 2006; Sawai, Okada et al. 2006). Each of these approaches has yielded insights into the cellular role of ILK and the cell functions it can influence. The siRNA approach to suppression of ILK gene expression is typically transient. By contrast, vector-expressing 
short hairpin RNA (shRNA) can suppress gene expression over extended periods (Brummelkamp, Bernards et al. 2002; Paddison, Caudy et al. 2002). The reduction of gene expression by stably expressing dominant negative mutants provides an alternative to obtain long-term effect of suppression. However, studies in which the expression of dominantnegative mutants are used must be interpreted cautiously in that deficient in binding to one or more of these proteins might give rise to incomplete or confusing results when used to assay certain functions for ILK (Vouret-Craviari, Boulter et al. 2004), since ILK has been found to bind to multiple partners through different functional domains (Wu 2001; Wu and Dedhar 2001), its multiple scaffolding capabilities must be considered. Our results demonstrated that RNA interference by using stably transfected ILK-shRNA vector is an effective way to knockdown ILK expression in VSMC used in the present study. There is also a limitation of using the shRNA approach, that the efficiency of gene knock-down could progressively decrease in the prolonged cell culture, even when the selection pressure was presented in culture. This limits the usage of shRNA transfected cells in very long term culture.

Phosphorylation of AKt and GSK-3 $\beta$ by ILK has been well-documented in the cancer cell survival and proliferation (Dedhar 2000; Duxbury, Ito et al. 2005; Nho, Xia et al. 2005; Qian, Zhong et al. 2005). In our experiment, knockdown of ILK expression by RNA interference decreases phosphorylation of serine ${ }^{473}$ of PKB/Akt and serine ${ }^{9}$ of GSK-3 $\beta$, and inhibits cell migration and proliferation, which is consistent with the findings in cancer cells, suggesting that the same ILK-signaling pathways could also play important roles in the VSMC proliferation. It has been shown that GSK-3 $\beta$ and AKt phosphorylation can be induced by acute pressurization in rat aortae (Rice, Kinnard et al. 2005), suggesting that GSK-3 $\beta$ and AKt phosphorylation could also be mechanosensitive. Given the role that ILK plays in integrin signaling, focal adhesion modulation, it could be a critical link in mediating the mechanical force induced phosphorylation of GSK-3 $\beta$ and AKt. Collectively, our data and studies by other groups all pointed that ILK is a critical multifaceted molecule in the intergrin-mechanotransduction signaling complex.

Several lines of recent data from transgenic mice (Grashoff, Aszodi et al. 2003; Sakai, Li et al. 2003; Terpstra, Prud'homme et al. 2003), C. elegans (Mackinnon, Qadota et al. 2002) and Drosophila (Zervas, Gregory et al. 2001) give rise to a strong evidence for a critical role of ILK in the modulation of cell spreading and adhesion. Our findings that VSMC stably expressing ILK-shRNA display increased cell spreading and adhesion demonstrate that ILK negatively regulates cell spreading and adhesion onto ECM. However, the evidence is not entirely consistent as ILK depletion was shown to impair cell attachment and spreading in fibroblasts and chondrocytes (Grashoff, Aszodi et al. 2003; Sakai, Li et al. 2003; Terpstra, Prud'homme et al. 2003). This inconsistency suggested that the ILK regulation of cell-ECM interactions may be dependent on the presence of other co-factors which may vary with cell types. In addition, it has been pointed out the effects of ILK are not all necessarily related to its kinase activity and may be more related to its scaffolding role at the focal adhesion (Ho and Bendeck 2009).

Focal adhesions are considered to be similar to VSMC attachment sites in the intact vessel wall termed dense plaques. These dense plaque regions contain 90 different proteins, including vinculin, paxillin, zyxin and protein tyrosine kinases such as focal adhesion kinase (FAK) and Src kinase (Liu, Calderwood et al. 2000; Zaidel-Bar, Itzkovitz et al. 2007). ILK knockdown have been shown to have a significant effect on the formation of focal adhesions (Geiger, Bershadsky et al. 2001; Zamir and Geiger 2001). In our study, ILK silencing in VSMC resulted in an increase in vinculin expression but a decrease in paxillin expression, and it also increased the number of focal adhesions, suggesting that ILK might be involved in modulation of focal adhesion formation or constituent protein turnover. It has been 
demonstrated that FAK and Src kinase play critical roles in regulating the turnover of focal adhesions (Ilic, Furuta et al. 1995; Volberg, Romer et al. 2001), with FAK- and Src-deficient cells showing a decrease in cell migration as well as an increase in the number of focal adhesions. Our results demonstrate that IK silencing in rat VSMC has a similar effect on focal adhesion formation and cell motility as the FAK or Src deficiency. The fact that VSMC migration was minimal in the presence of PDGF-BB is surprising, since PDGF-BB is known as a potent chemotactic of VSMC. This is possibly due to the fact that VSMC adhesion to the poly-l-lysine surface is not mediated by integrins. This could hinder the cell mobility in short-term experiment (i.e. 3 hours) and interfere with detection of PDGF action. In contrast, the presence of FN did provide cell surface integrins with adhesion sites and did facilitate VSMC migration.

It has been shown that ILK-deficient fibroblasts displayed abnormal F-actin aggregates and delayed formation of stress fibers (Sakai, Li et al. 2003). In our experiments, no significant difference with regard to actin cytoskeleten organization was observed between ILK-shRNA and non-silencing control cells (data not shown). Our results are in agreement with the report that there are only minor differences with respect to actin organization among cell lines transfected with E359K ILK (DN-ILK), S343A ILK (kinase-dead ILK) or PBS ILK (paxillin binding mutant) (Khyrul, LaLonde et al. 2004).

In conclusion, our data demonstrate that in VSMC from resistance arterioles that ILK is involved in cell spreading, adhesion, migration and focal contact formation. In addition, our data with the AFM directly demonstrate that ILK silencing enhanced integin-FN adhesion, increased the elasticity of FN-integrin focal adhesions and enhanced mechanoresponsiveness of focal adhesions to mechanical force, as evidenced by generation of cell contractile forces to oppose the pulling forces applied with the AFM. From the collected observations reported here, it is tempting, as speculation, to propose that in small resistance arterioles, ILK activity may normally support cell behavior consistent with arterial injury, such as, increased proliferation, migration, less spreading and reduced adhesion. Clearly, additional work is needed to more completely understand ILK and its many roles in the smooth muscle cell.

\section{Acknowledgments}

This work was supported by National Institute of Health (NIH) Grant HL-058690 to G. A. Meininger. We thank Drs. Cary Wu and Min Lee for providing plasmids.

\section{References}

Adams JC. Cell-matrix contact structures. Cell Mol Life Sci. 2001; 58(3):371-92. [PubMed: 11315186]

Attwell S, Mills J, et al. Integration of cell attachment, cytoskeletal localization, and signaling by integrin-linked kinase (ILK), CH-ILKBP, and the tumor suppressor PTEN. Mol Biol Cell. 2003; 14(12):4813-25. [PubMed: 12960424]

Brakebusch C, Fassler R. The integrin-actin connection, an eternal love affair. EMBO J. 2003; 22(10): 2324-33. [PubMed: 12743027]

Brummelkamp TR, Bernards R, et al. A system for stable expression of short interfering RNAs in mammalian cells. Science. 2002; 296(5567):550-3. [PubMed: 11910072]

Chao JT, Martinez-Lemus LA, et al. Modulation of alpha7-integrin-mediated adhesion and expression by platelet-derived growth factor in vascular smooth muscle cells. Am J Physiol Cell Physiol. 2006; 290(4):C972-80. [PubMed: 16282198]

Dedhar S. Cell-substrate interactions and signaling through ILK. Curr Opin Cell Biol. 12(2):250-6. [PubMed: 10712922] 
Delcommenne M, Tan C, et al. Phosphoinositide-3-OH kinase-dependent regulation of glycogen synthase kinase 3 and protein kinase B/AKT by the integrin-linked kinase. Proc Natl Acad Sci U S A. 1998; 95(19):11211-6. [PubMed: 9736715]

Deng JT, Van Lierop JE, et al. Ca2+-independent smooth muscle contraction. a novel function for integrin-linked kinase. J Biol Chem. 2001; 276(19):16365-73. [PubMed: 11278951]

Duxbury MS, Ito $\mathrm{H}$, et al. RNA interference demonstrates a novel role for integrin-linked kinase as a determinant of pancreatic adenocarcinoma cell gemcitabine chemoresistance. Clin Cancer Res. 2005; 11(9):3433-8. [PubMed: 15867245]

Dwivedi A, Sala-Newby GB, et al. Regulation of cell-matrix contacts and beta-catenin signaling in VSMC by integrin-linked kinase: implications for intimal thickening. Basic Res Cardiol. 2008; 103(3):244-56. [PubMed: 18080083]

Falcone JC, Davis MJ, et al. Endothelial independence of myogenic response in isolated skeletal muscle arterioles. Am J Physiol. 1991; 260(1 Pt 2):H130-5. [PubMed: 1992791]

Friedrich EB, Clever YP, et al. Role of integrin-linked kinase in vascular smooth muscle cells: regulation by statins and angiotensin II. Biochem Biophys Res Commun. 2006; 349(3):883-9. [PubMed: 16962068]

Geiger B, Bershadsky A, et al. Transmembrane crosstalk between the extracellular matrix-cytoskeleton crosstalk. Nat Rev Mol Cell Biol. 2001; 2(11):793-805. [PubMed: 11715046]

Grashoff C, Aszodi A, et al. Integrin-linked kinase regulates chondrocyte shape and proliferation. EMBO Rep. 2003; 4(4):432-8. [PubMed: 12671688]

Hannigan GE, Leung-Hagesteijn C, et al. Regulation of cell adhesion and anchorage-dependent growth by a new beta 1-integrin-linked protein kinase. Nature. 1996; 379(6560):91-6. [PubMed: 8538749]

Ho B, Bendeck MP. Integrin linked kinase (ILK) expression and function in vascular smooth muscle cells. Cell Adh Migr. 2009; 3(2):174-6. [PubMed: 19262169]

Ho B, Hou G, et al. Integrin-linked kinase in the vascular smooth muscle cell response to injury. Am J Pathol. 2008; 173(1):278-88. [PubMed: 18535176]

Hynes RO. Integrins: bidirectional, allosteric signaling machines. Cell. 2002; 110(6):673-87. [PubMed: 12297042]

Ilic D, Furuta Y, et al. Reduced cell motility and enhanced focal adhesion contact formation in cells from FAK-deficient mice. Nature. 1995; 377(6549):539-44. [PubMed: 7566154]

Ishii $\mathrm{T}$, Furuoka $\mathrm{H}$, et al. Inactivation of integrin-linked kinase induces aberrant tau phosphorylation via sustained activation of glycogen synthase kinase 3beta in N1E-115 neuroblastoma cells. J Biol Chem. 2003; 278(29):26970-5. [PubMed: 12714590]

Khyrul WA, LaLonde DP, et al. The integrin-linked kinase regulates cell morphology and motility in a rho-associated kinase-dependent manner. J Biol Chem. 2004; 279(52):54131-9. [PubMed: 15485819]

Legate KR, Montanez E, et al. ILK, PINCH and parvin: the tIPP of integrin signalling. Nat Rev Mol Cell Biol. 2006; 7(1):20-31. [PubMed: 16493410]

Leung-Hagesteijn C, Hu MC, et al. Integrin-linked kinase mediates bone morphogenetic protein 7dependent renal epithelial cell morphogenesis. Mol Cell Biol. 2005; 25(9):3648-57. [PubMed: 15831470]

Liu S, Calderwood DA, et al. Integrin cytoplasmic domain-binding proteins. J Cell Sci. 2000; 113(Pt 20):3563-71. [PubMed: 11017872]

Lo SH. Focal adhesions: what's new inside. Dev Biol. 2006; 294(2):280-91. [PubMed: 16650401]

Lynch DK, Ellis CA, et al. Integrin-linked kinase regulates phosphorylation of serine 473 of protein kinase B by an indirect mechanism. Oncogene. 1999; 18(56):8024-32. [PubMed: 10637513]

Mackinnon AC, Qadota H, et al. C. elegans PAT-4/ILK functions as an adaptor protein within integrin adhesion complexes. Curr Biol. 2002; 12(10):787-97. [PubMed: 12015115]

Muranyi A, MacDonald JA, et al. Phosphorylation of the myosin phosphatase target subunit by integrin-linked kinase. Biochem J. 2002; 366(Pt 1):211-6. [PubMed: 12030846] 
Nho RS, Xia H, et al. Role of integrin-linked kinase in regulating phosphorylation of Akt and fibroblast survival in type I collagen matrices through a betal integrin viability signaling pathway. J Biol Chem. 2005; 280(28):26630-9. [PubMed: 15905178]

Paddison PJ, Caudy AA, et al. Stable suppression of gene expression by RNAi in mammalian cells. Proc Natl Acad Sci U S A. 2002; 99(3):1443-8. [PubMed: 11818553]

Qian Y, Zhong X, et al. ILK mediates actin filament rearrangements and cell migration and invasion through PI3K/Akt/Rac1 signaling. Oncogene. 2005; 24(19):3154-65. [PubMed: 15735674]

Radmacher M. Measuring the elastic properties of biological samples with the AFM [see comments]. IEEE Eng Med Biol Mag. 1997; 16(2):47-57. [PubMed: 9086372]

Rice KM, Kinnard RS, et al. Aging alters vascular mechanotransduction: pressure-induced regulation of p70S6k in the rat aorta. Mech Ageing Dev. 2005; 126(11):1213-22. [PubMed: 16087221]

Rosano L, Spinella F, et al. Integrin-linked kinase functions as a downstream mediator of endothelin-1 to promote invasive behavior in ovarian carcinoma. Mol Cancer Ther. 2006; 5(4):833-42. [PubMed: 16648553]

Sakai T, Li S, et al. Integrin-linked kinase (ILK) is required for polarizing the epiblast, cell adhesion, and controlling actin accumulation. Genes Dev. 2003; 17(7):926-40. [PubMed: 12670870]

Sawai H, Okada Y, et al. Integrin-linked kinase activity is associated with interleukin-1 alpha-induced progressive behavior of pancreatic cancer and poor patient survival. Oncogene. 2006; 25(23): 3237-46. [PubMed: 16407822]

Schwartz MA. Integrins, oncogenes, and anchorage independence. J Cell Biol. 1997; 139(3):575-8. [PubMed: 9348275]

Sun Z, Martinez-Lemus LA, et al. Extracellular matrix-specific focal adhesions in vascular smooth muscle produce mechanically active adhesion sites. Am J Physiol Cell Physiol. 2008; 295(1):C268-78. [PubMed: 18495809]

Sun Z, Martinez-Lemus LA, et al. Mechanical properties of the interaction between fibronectin and alpha5beta1-integrin on vascular smooth muscle cells studied using atomic force microscopy. Am J Physiol Heart Circ Physiol. 2005; 289(6):H2526-35. [PubMed: 16100245]

Terpstra L, Prud'homme J, et al. Reduced chondrocyte proliferation and chondrodysplasia in mice lacking the integrin-linked kinase in chondrocytes. J Cell Biol. 2003; 162(1):139-48. [PubMed: 12835312]

Trache A, Trzeciakowski JP, et al. Histamine effects on endothelial cell fibronectin interaction studied by atomic force microscopy. Biophys J. 2005; 89(4):2888-98. [PubMed: 16055535]

Troussard AA, Mawji NM, et al. Conditional knock-out of integrin-linked kinase demonstrates an essential role in protein kinase B/Akt activation. J Biol Chem. 2003; 278(25):22374-8. [PubMed: 12686550]

Volberg T, Romer L, et al. pp60(c-src) and related tyrosine kinases: a role in the assembly and reorganization of matrix adhesions. J Cell Sci. 2001; 114(Pt 12):2279-89. [PubMed: 11493667]

Vouret-Craviari V, Boulter E, et al. ILK is required for the assembly of matrix-forming adhesions and capillary morphogenesis in endothelial cells. J Cell Sci. 2004; 117(Pt 19):4559-69. [PubMed: 15316070]

Wang N, Butler JP, et al. Mechanotransduction across the cell surface and through the cytoskeleton. Science. 1993; 260(5111):1124-7. [PubMed: 7684161]

Wilson DP, Sutherland C, et al. Integrin-linked kinase is responsible for Ca2+-independent myosin diphosphorylation and contraction of vascular smooth muscle. Biochem J. 2005; 392(Pt 3):641-8. [PubMed: 16201970]

Wu C. ILK interactions. J Cell Sci. 2001; 114(Pt 14):2549-50. [PubMed: 11683382]

Wu C. The PINCH-ILK-parvin complexes: assembly, functions and regulation. Biochim Biophys Acta. 2004; 1692(2-3):55-62. [PubMed: 15246679]

Wu C, Dedhar S. Integrin-linked kinase (ILK) and its interactors: a new paradigm for the coupling of extracellular matrix to actin cytoskeleton and signaling complexes. J Cell Biol. 2001; 155(4):50510. [PubMed: 11696562]

Wu X, Mogford JE, et al. Modulation of calcium current in arteriolar smooth muscle by alphav beta3 and alpha5 beta1 integrin ligands. J Cell Biol. 1998; 143(1):241-52. [PubMed: 9763435] 
Xu Z, Fukuda T, et al. Molecular dissection of PINCH-1 reveals a mechanism of coupling and uncoupling of cell shape modulation and survival. J Biol Chem. 2005; 280(30):27631-7. [PubMed: 15941716]

Zaidel-Bar R, Cohen M, et al. Hierarchical assembly of cell-matrix adhesion complexes. Biochem Soc Trans. 2004; 32(Pt3):416-20. [PubMed: 15157150]

Zaidel-Bar R, Itzkovitz S, et al. Functional atlas of the integrin adhesome. Nat Cell Biol. 2007; 9(8): 858-67. [PubMed: 17671451]

Zamir E, Geiger B. Components of cell-matrix adhesions. J Cell Sci. 2001; 114(Pt 20):3577-9. [PubMed: 11707509]

Zervas CG, Gregory SL, et al. Drosophila integrin-linked kinase is required at sites of integrin adhesion to link the cytoskeleton to the plasma membrane. J Cell Biol. 2001; 152(5):1007-18. [PubMed: 11238456]

Zhang W, Wu Y, et al. Integrin-linked kinase regulates N-WASp-mediated actin polymerization and tension development in tracheal smooth muscle. J Biol Chem. 2007; 282(47):34568-80. [PubMed: 17897939]

Zhang Y, Ikegami T, et al. Involvement of integrin-linked kinase in carbon tetrachloride-induced hepatic fibrosis in rats. Hepatology. 2006; 44(3):612-22. [PubMed: 16941698] 


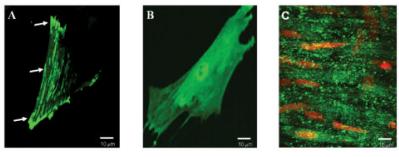

Figure 1.

Confocal fluorescent images of cultured vascular smooth muscle cells transfected with EGFP-ILK (A) or EGFP alone (B). EGFP-ILK was localized to focal adhesion sites (arrows). In comparison, EGFP alone was diffusely dispersed throughout the cell. (C) Immunofluorescent labeling showed the presence of ILK (green) in the vascular smooth muscle of an intact, isolated and pressurized rat cremaster feed arteriole. The ILK is apparent as punctate labeling on the cell surface as well as some diffuse labeling in the cytosol. The cell nuclei were shown in red. Scale bar $=10 \mu \mathrm{m}$. 

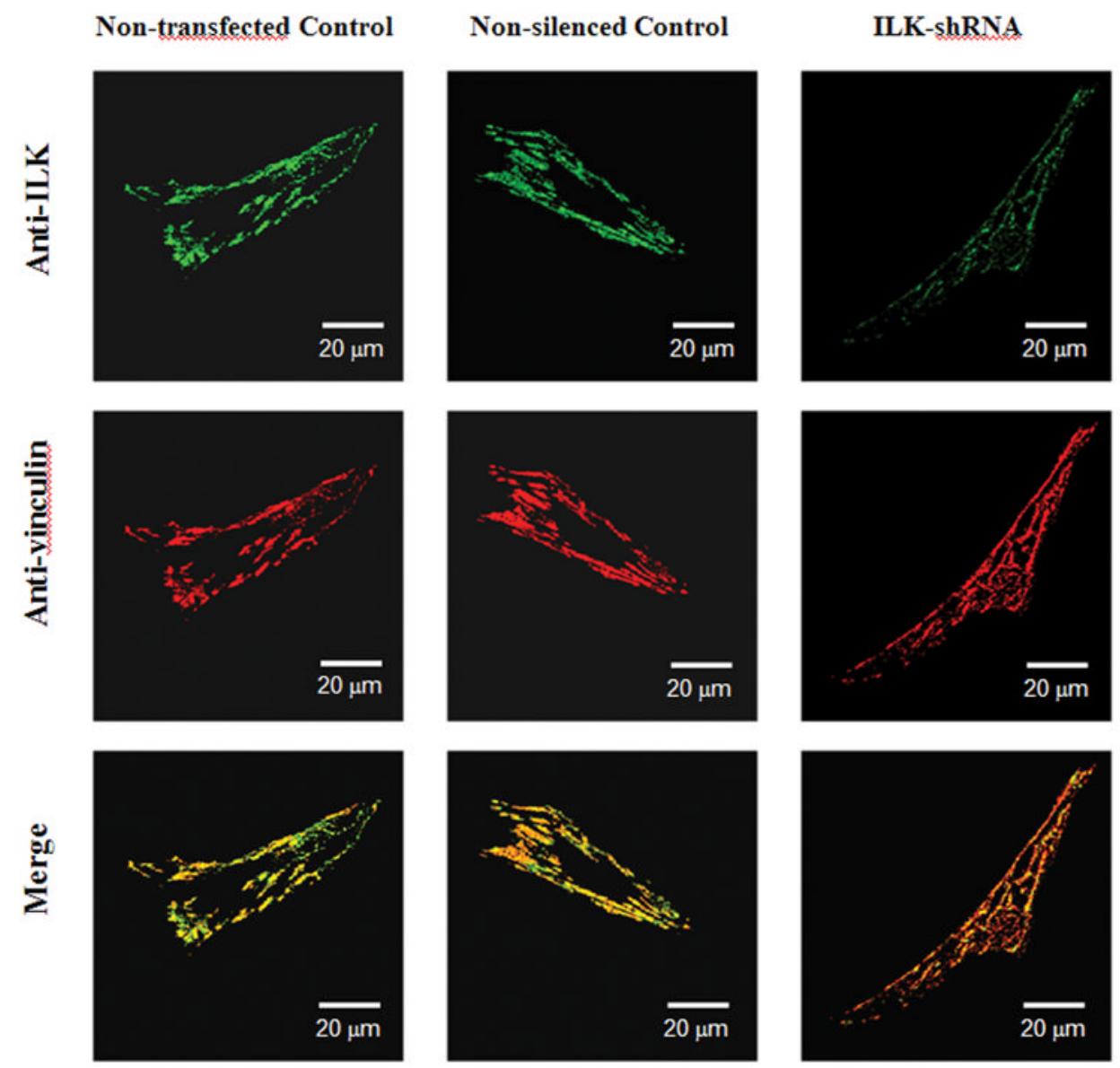

Figure 2.

Immunofluorescent images of vascular smooth muscle cells probed with anti-ILK and antivinculin antibodies showed that ILK colocalized with focal adhesion protein vinculin at focal adhesions. Results are representative of three independent experiments. Scale bar $=30$ $\mu \mathrm{m}$. Colocalization index was calculated with Olympus FV1000 software and was presented as a mean \pm SE of 10 cells. Non-transfected control, cells were cultured less than 10 passages and not transfected (Colocalization index, $0.56 \pm 0.02$ ); Non-silenced control cells, cells were cultured between 10 and 20 passages and transfected with non-silenced control construct (Colocalization index, $0.73 \pm 0.01$ ); ILK-shRNA, cells were cultured between 10 and 20 passages and transfected with ILK-shRNA silencing construct (Colocalization index, $0.69 \pm 0.02)$. As shown, ILK localizations in VSMC were not affected by transfection with either non-silenced or ILK-shRNA constructs. 
A

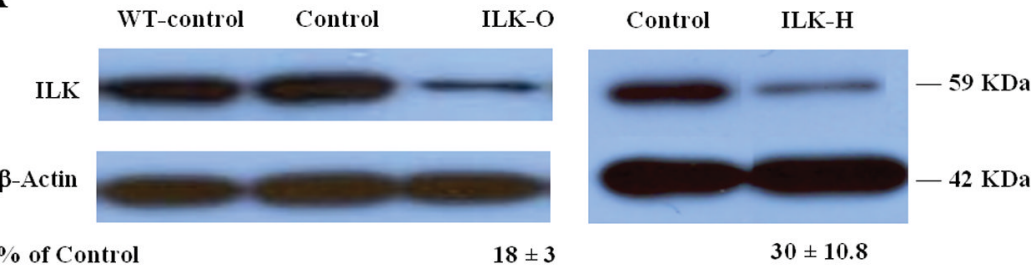

B

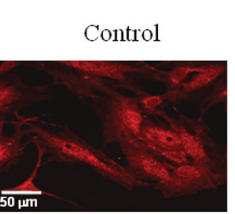

ILK-O-shRNA

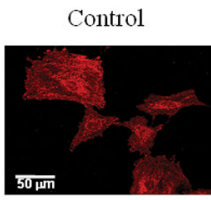

ILK-H-shRNA

C

Control ILK-O

D
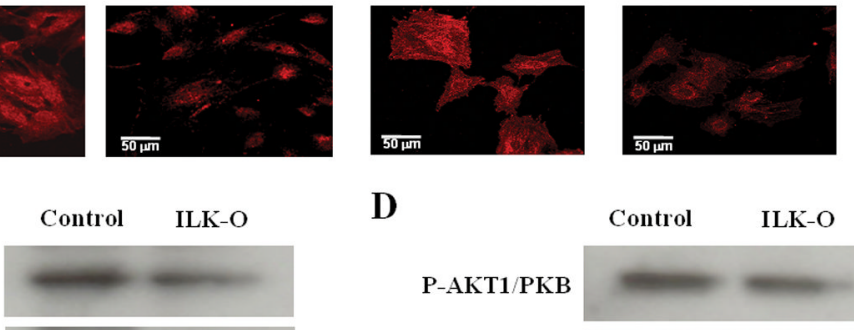

D

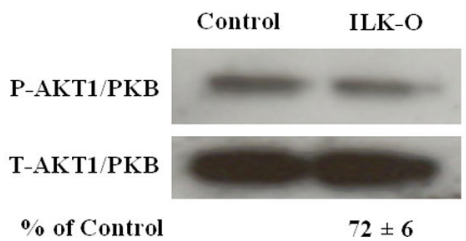

Figure 3.

(A) and (B) Western blots and immunofluorescence probed with an anti-ILK antibody showed that ILK expression was knocked down in VSMC stably transfected with ILK-O and ILK-H construct compared to cells transfected with non-silenced control (A control of non-transfected cells: WT-control, is also included in Western blotting). Images were taken with a $40 \times 1.30$ objective. Scale bar $=50 \mu \mathrm{m}$. Blots were quantified and normalized to $\beta$ actin and displayed as percent of control. (C) and (D): ILK silencing reduces phosphorylation of GSK-3 $\beta$ and AKT1/PKB in VSMC stably transfected with ILK-O construct compared to cells transfected with non-silenced control. Western blots were probed with antibodies against phospho-specific GSK-3 $\beta$ (P-GSK-3 $\beta$ ), total GSK-3 $\beta$ (TGSK-3 $\beta$ ), phospho-specific AKT1/PKB (P-AKT1/PKB) and total AKT1/PKB(T-AKT1/ PKB). Blots were quantified and normalized to total GSK-3 $\beta$ or total AKT1/PKB and displayed as percent of the control. The results are representative of 3 independent experiments. 
A
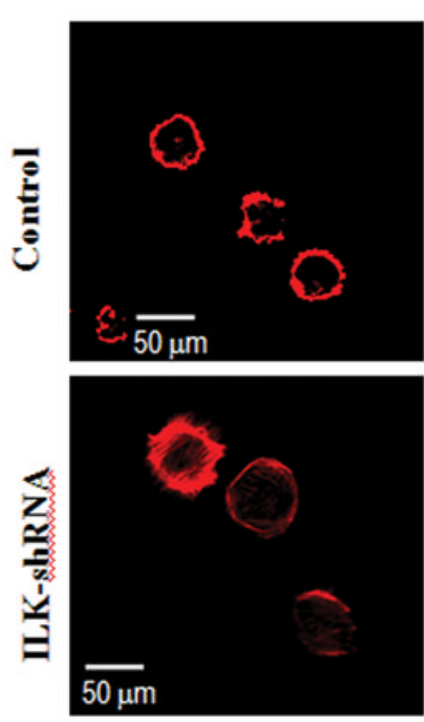

$3 \mathrm{~h}$
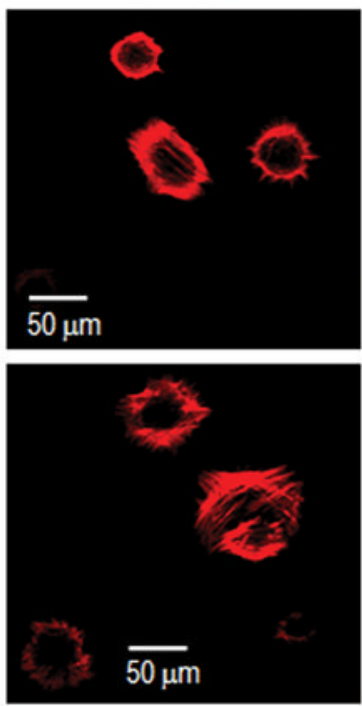

$5 h$
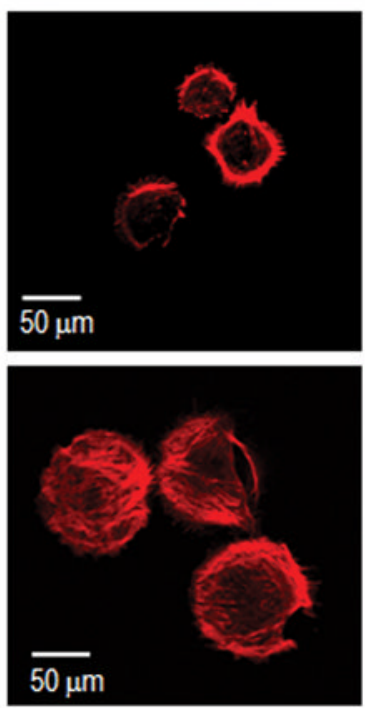

B $\square$ Control

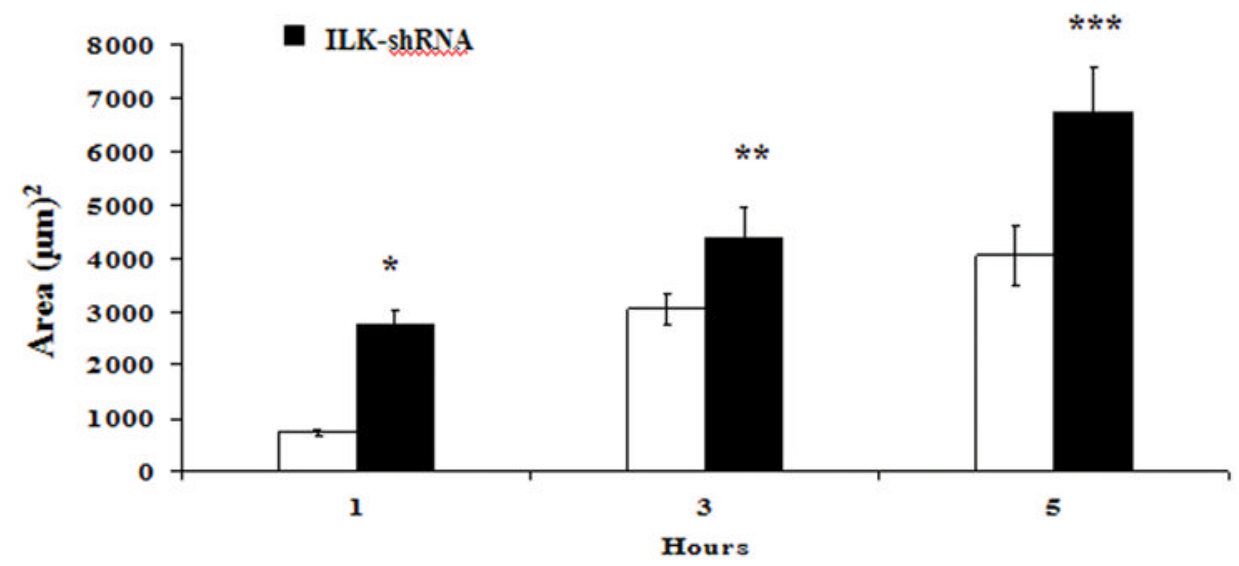

Figure 4. ILK silencing promotes VSMC spreading

(A) VSMC stably transfected with non-silenced control and ILK-shRNA constructs were plated with serum-free culture medium on $50 \mu \mathrm{g} / \mathrm{ml}$ fibronectin-coated dishes for 1,3 and $5 \mathrm{~h}$ and were then fixed and stained with Alexa 568-conjugated-phalloidin. (B) Bar graphs representing mean cell areas (in square micrometers) calculated using Image J. (*, p<0.001 vs. control; **, p<0.01 vs. control; ***, p<0.05 vs. control). Error bars represent standard error of the mean. ILK silencing increases cell spreading in ILK-shRNA cells in comparison with non-silencing control. Images were taken with a $40 \times 1.30$ objective. Results are representative of 4 independent experiments. Scale bar $=50 \mu \mathrm{m}$. 


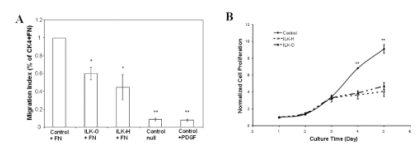

Figure 5. ILK silencing inhibits cell migration and proliferation of VSMC

(A) Migration assays were carried out in Boyden migration chamber with VSMCs transfected with non-silenced control and ILK-shRNA constructs (ILK-O and ILK-H). The stimulants in lower chambers are as follows: null: un-stimulated control; PDGF: PDGF, 2.5 $\mu \mathrm{g} / \mathrm{ml}$; FN: $50 \mu \mathrm{g} / \mathrm{ml}$ fibronectin. Data are displayed as an index relative to the control in equivalent condition. Results are based on at least 3 independent experiments performed at least in quadruplicate. (B) Proliferation assays of control and ILK-O transfected VSMC using cell counting. Error bars represent the standard error between experiments. * $\mathrm{p}<0.05$, $\mathrm{n}=3 ; * * \mathrm{p}<0.01, \mathrm{n}=5$. 


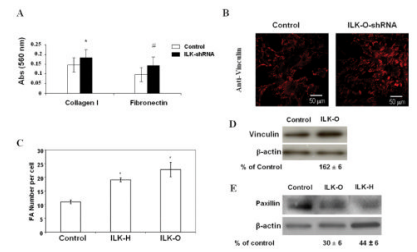

Figure 6. ILK silencing enhances cell adhesion in VSMC

(A) Control or ILK-shRNA constructs stably transfected VSMC were plated in 96-well plates coated with $50 \mu \mathrm{g} / \mathrm{ml}$ collagen type I or $50 \mu \mathrm{g} / \mathrm{ml} \mathrm{FN}$ and allowed to adhere for $1 \mathrm{~h}$.

Results represent mean \pm SE of 6 independent experiments. ( $^{*}, \mathrm{p}<0.05$ vs. control; \#, p<0.05 vs. control). (B) VSMC stably transfected with non-silened control and ILK-shRNA construct (ILK-O) were plated with serum-free culture medium on $50 \mu \mathrm{g} / \mathrm{ml} \mathrm{FN}$-coated dishes and immunofluorescence was probed with anti-vinculin antibody. Images were taken with a $40 \times 1.30$ objective. Scale bar $=50 \mu \mathrm{m}$. Results are representative of 4 independent experiments. (C) Focal adhesion number was quantified using NIH Image $\mathbf{J}$ as described in Materials and Methods. Values are mean of focal adhesions per cell. ( $n=22, p<0.01$ vs. control). (D) Western blots showed that vinculin expression is increased in ILK-O VSMC in comparison with non-silenced control (162 $\pm 6 \%$ of control). (E) paxillin expression is decreased in ILK-O and ILK-H VSMC in comparison with non-silenced control (162 $\pm 6 \%$ of control). Blots were quantified and normalized to actin and displayed as percent of the control. Results are representative of 3 independent experiments, $p<0.05$ for both vinculin and paxillin blotts. 


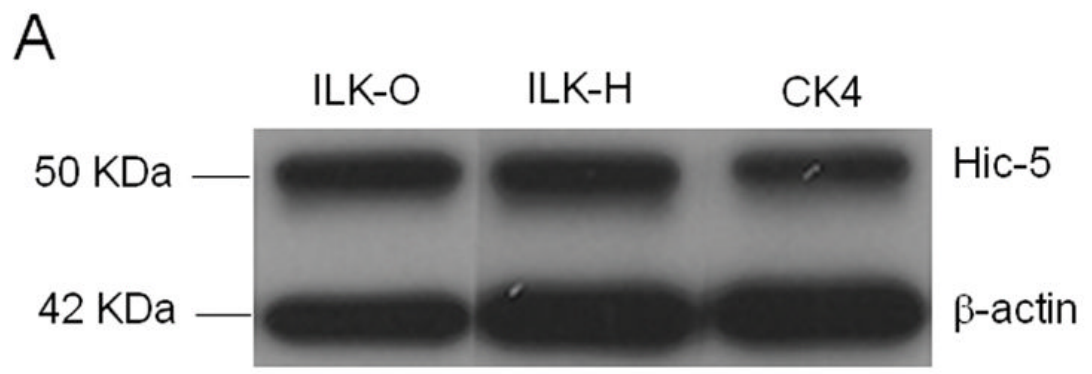

B

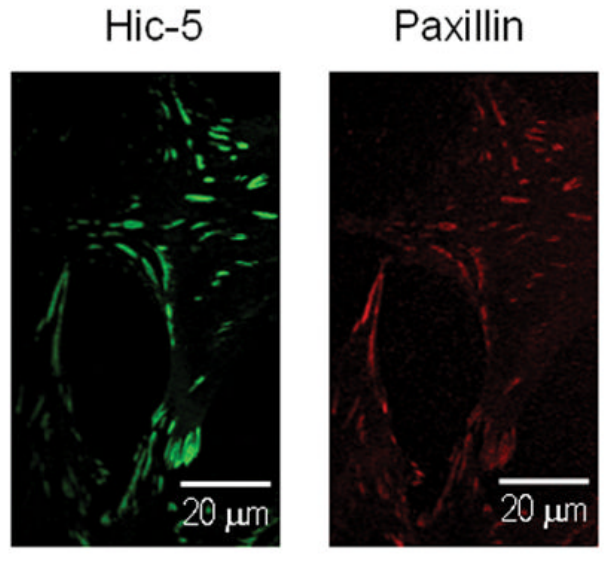

Control
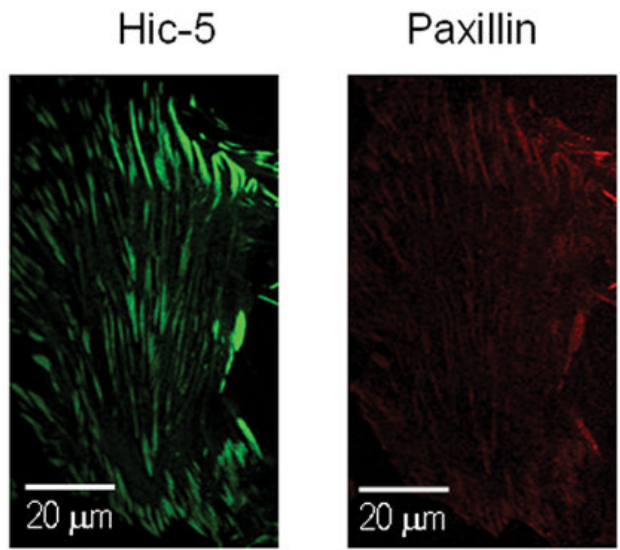

ILK-H shRNA

Figure 7.

(A) Western blot showing that Hic-5 Expression was enhanced in ILK-O and ILK-H comparing to control. (B) Immunofluorescece confocal images of paxillin and Hic-5 at VSMC focal adhesions. Paxillin was labeled with K-20 antibody, Alexa-647; and Hic-5 was labeled with 34/Hic-5, Alexa-488. Both paxillin and hic-5 were localized at focal adhesions in either control or ILK knock-down VSMCs. Similar results were observed in ILK-O VSMCs (data not shown). 

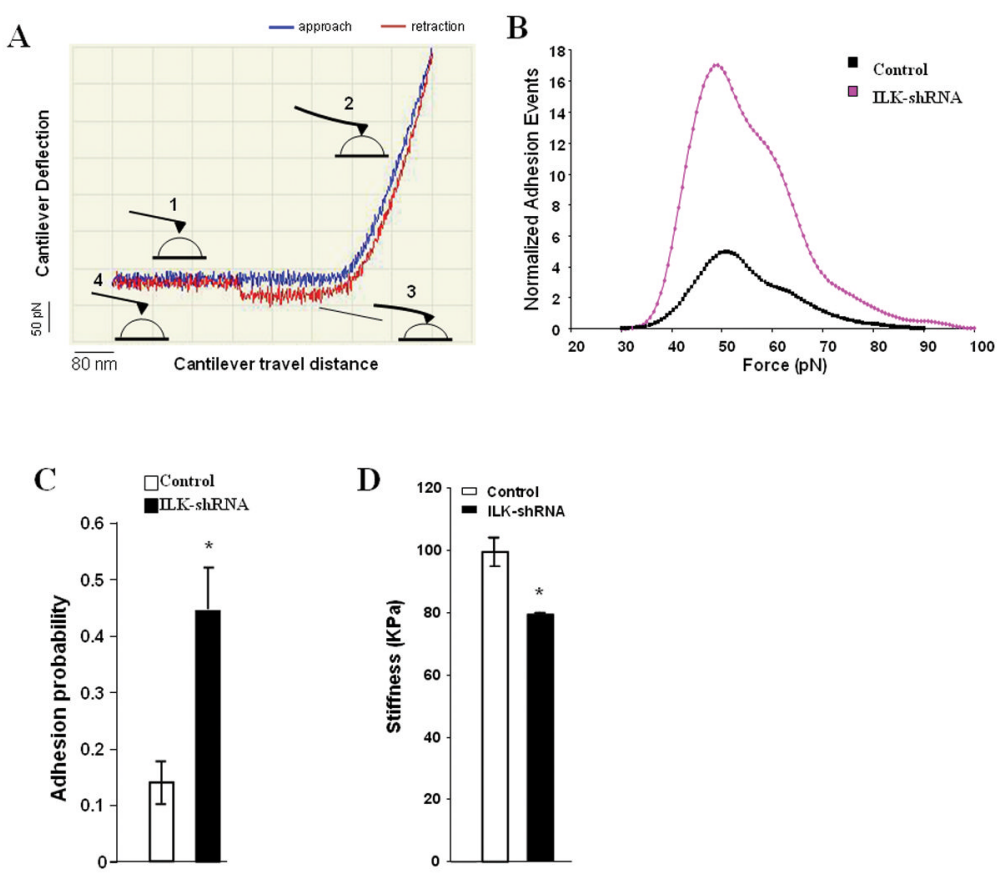

Figure 8.

(A) A typical AFM recorded force curve. The probe was coated with FN, and an adhesion event is detected by the "snap-off" in the retraction curve. The compression stiffness was measured by fitting the approaching curve with Hertz model. (B) The adhesion forces (unbinding or rupture forces) distribution plotted as a histogram. (C) The probability of binding was determined as (number of force curves with adhesions)/(total number of force curves). Error bars represent standard error of the mean. Compared to control VSMC, ILKshRNA cells exhibited an increased probability of binding to fibronectin but the adhesion force distribution was not significantly different. (D) Stiffness of control and ILK-O cells. Error bars represent standard error of the mean. *: $\mathrm{p}<0.05$. 


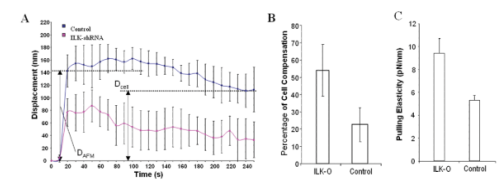

Figure 9. ILK silencing enhanced pulling force response in VSMC

(A) The AFM cantilever with FN-coated bead was brought into contact with the cell surface of VSMC (control or ILK-O). The bead was then pulled from the cell surface using the AFM in the Z-axis, and the bead displacement over 250 seconds was shown to indicate the VSMC response to the pulling force. Error bars represent standard error of the mean. $(n=5$, $\mathrm{p}<0.05$ vs. control). (B) Percentage of cell compensation as an indicator of quantified cellular micro-myogenic response. (C) Apparent pulling elasticity as an indicator of the strength of the focal adhesion and the associated cytoskeleton underneath. Error bars represent standard error of the mean. 